\title{
Do brega paraense ao tecnobrega: história e tradição na websérie Sampleados
}

Rafael José Azevedo

Resumo: O artigo trata da websérie musical Sampleados. A partir da descrição de seus episódios, discutimos possíveis relações entre história e música popular feita no Brasil. A série foi ao ar em 2015 e, indiretamente, nos conta parte da história do brega paraense ao apresentar, em suas narrativas, artistas e canções supostamente importantes para o fenômeno desde os anos 1980. Ao convocar determinado passado, Sampleados apresenta o brega como uma espécie de tradição musical. Sendo assim, buscamos evidenciar as contradições que permeiam as narrativas históricas a partir do pensamento de Paul Ricoeur.

Palavras-Chave: música popular; brega paraense; tecnobrega; tradição.

Abstract: From "brega paraense" to "tecnobrega": history and tradition at the web series Sampleados

-- This paper examines a musical web series Sampleados. Describing its episodes, we discussed possible links between history and popular music made in Brazil. The series was broadcast in 2015 and, indirectly, tells us part of the history of the style called "brega paraense" by introducing, in its narratives, songs and artists considered representatives of the phenomenon since the 1980s. By invoking certain past, Sampleados presents the "brega" as a kind of musical tradition. Therefore we seek to highlight the contradictions that permeate historical narratives from the contributions of Paul Ricoeur.

Key words: popular music; brega paraense; tecnobrega; cultural tradition.

\section{Introdução}

A ideia desse artigo é refletir sobre possíveis relações entre música popular e tradição a partir da observação de uma série audiovisual que nos apresenta a proposta de 
uma história do brega paraense. Trata-se de um conjunto de vídeos intitulado Sampleados assinado pela produtora paraense Platô Produções que foi ao ar pelo YouTube entre junho e outubro de 2015. São cinco episódios musicais em que artistas de diferentes gerações participam de pequenas cenas ambientadas em diversas locações na cidade de Belém do Pará cantando bregas marcantes em medleys produzidos pelo DJ e cantor Will Love. A sonoridade das canções faz referência direta ao tecnobrega e os vídeos são como sketches que duram entre 3 e 5 minutos aproximadamente que figuram, nas imagens, os sentidos invocados nas letras quase que didaticamente.

No campo de descrição do primeiro episódio no YouTube temos:

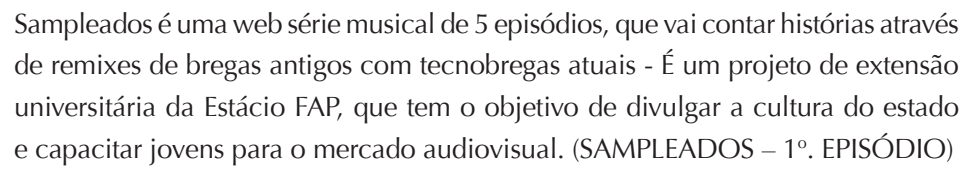

Há um aspecto que nos chama atenção nessa fala: a relação estabelecida tacitamente entre a música brega e o Estado do Pará. Esse gênero musical, se assim pudermos considerá-lo, é algo que viemos percebendo como índice identitário cultural que parece ajudar a erigir certo imaginário em torno de práticas ligadas à música popular desse Estado brasileiro junto de outras expressões tais como o carimbó, a lambada e a guitarrada. Outro aspecto importante é a articulação feita pelos produtores à ideia de websérie. Paula Hernández García observa o surgimento e os caminhos tomados por esse formato audiovisual no contexto espanhol propondo uma caracterização que nos parece pertinente:
Tomamos websérie como todos aqueles seriados de ficção audiovisual criados para serem emitidos na Internet. Com uma unidade argumentativa, certa continuidade (pelo menos temática) e mais de três capítulos (GARCíA, 2011, p. 95, no original em espanhol)

De acordo ainda com essa autora, o YouTube, já em 2011, apresentava-se como a principal plataforma para a veiculação dessas narrativas que, mesmo fazendo referências claras a formatos audiovisuais já consolidados, possui características algo específicas -- com destaque para a curta duração de episódios e também para o baixo custo de produção que os envolve.

Partindo disso, o texto se articula em três movimentos: descrevemos as edições da websérie a fim de apontar elementos que nos parecem pertinentes para ensaiarmos uma análise. Em seguida, discutimos como a série pode ser entendida como uma espécie de narrativa historiográfica do brega paraense ao apresentar aquelas que seriam suas heranças. Por fim, notamos como o Sampleados articula um gesto de rememoração algo resistente na medida em que propõe historicizar um fenômeno musical minoritário diante de uma historiografia mais hegemônica que trata de nossa música popular. 


\section{Sampleados: encenando canções}

Na descrição do primeiro episódio do Sampleados no YouTube, temos: "Com Betty Dopazo, Wanderley Andrade e participação especial da dupla Leona Vingativa e Aleijada Hipócrita, o primeiro episódio da Websérie Sampleados chega botando o astro do brega pra fora de casa." (SAMPLEADOS - 1². EPISÓDIO, 2015). No início, o cantor Wanderley Andrade caminha trôpego, com uma garrafa de cachaça na mão, até o portão de uma casa e mira uma espécie de laje onde se posicionam outras três personagens: é como se fosse uma serenata. A personagem representada pela agitadora cultural Betty Dopazo é acompanhada por Leona Vingativa e Aleijada Hipócrita, que não cantam. A trama toda se desenrola a partir de um aparente desentendimento: Wanderley, ao cantar canções como Eu te amo, meu amor (1994) de Frankito Lopes e Um drink no bar (2008) da banda Conexão, tenta entrar na casa, bem como convencer Betty Dopazo de seu amor e de sua inocência. Em contrapartida, ela nega as declarações cantando canções como Você vacilou (2009), dos Irmãos Metralha, e Conquista (2002), do próprio Wanderley, que funcionam como acusações contra ele. Ao final da sequência, a atriz fecha o portão da casa na cara do cantor.

A descrição do segundo episódio no YouTube nos informa: "Com Suanny Batidão (Banda Anjos do Melody), Will Love e Waldo Squash (Gang do Eletro), o segundo episódio da Websérie Sampleados te ensina que nem todo Nego Lindo é sortudo e que o Rupinol é uma droga perigosa." (SAMPLEADOS - 2. EPISÓDIO, 2015). Na trama, um sujeito vestindo terno e gravata é enganado pela cantora Suanny dentro do bar Meu Garoto, tradicional reduto boêmio de Belém. Ao cantar canções como Cadê o corno? (2009) creditada à Banda Viper, Ultra Som (2009) da Banda Ravelly e Nego Lindo creditada a Lene Bandeira, a personagem o seduz dançando sensualmente na sua frente. A participação dos garçons cantando Rupinol, do cantor Marinho, é o que indica mais claramente as intenções da mulher: drogar o sujeito e roubar-lhe vários pertences. O episódio termina com os garçons Waldo Squash e Will Love zombando do homem desacordado.

O terceiro episódio se passa no mercado Ver-o-Peso em Belém. O clima é de verão, a descrição do vídeo informa:

\footnotetext{
May Souza (Banda AR-15), Renan Sanches (Banda ARK), Letícia Diogo e Felix Robatto se reuniram para se divertir e tomar uma gelada no Ver-o-Peso, até que a Varejeira Nanna Reis aparece e arrebata o coração da galera da golada, inclusive do gringo Leo Chermont. (SAMPLEADOS $-3^{\circ}$. EPISÓDIO, 2015)
}

No início, os personagens se encontram sentados tomando cerveja em um bar. Há também imagens do guitarrista Leo Chermont da banda Strobo de óculos escuros diante da Baía do Guajará tirando fotos em sua câmera. A canção Galera da golada (2009), 
de Viviane Batidão, cantada por May Souza e Letícia Diogo, é seguida de Quem vai querer a minha piriquita (2009), da Banda Katrina, cantada por Nanna Reis. Essa personagem é peça chave por ser descrita como uma mulher interesseira quando Félix Robatto e Renan Sanches cantam, respectivamente, Brega da varejeira (2002) -- não descobrimos de que banda -- e Varejeira da Banda Xeiro Verde de 1998. Na sequência, há uma pequena menção ao refrão da canção Gererê, de Nelsinho Rodrigues, cantada por Renan logo antes do final do vídeo em que Nanna Reis seduz o turista enquanto canta Gringo lindo creditada à Banda Floresta Amazônica na página do YouTube'.

No penúltimo episódio, contracenam dois músicos apenas: "Thaciane Pantoja (Banda Batidão do Melody) resolve fugir da escola para esperar ansiosa a chegada do seu amado Tony Brasil, o criador do tecnomelody. O bole rebole rola solto até que chega a hora de dizer 'Tchau Amor'." (SAMPLEADOS - 4. EPISÓDIO, 2015). A trama é simples: ao cantar os versos de Tic tic tac da Banda Amazonas na abertura, notamos que a colegial Thaciane Pantoja espera por alguém. Este chega em Belém através de uma pequena embarcação aportando próximo ao Ver-o-Peso. Ele se declara à estudante através dos versos de Meu amor é todo seu da Banda Sayonara: eles fazem um dueto na canção enquanto imagens dele no barco e dela na beira do rio se entrecortam até que se encontram no porto. Na sequência, o casal se encontra dentro de um quarto enquanto dançam e cantam, em dueto, a canção Bole rebole (2002) ${ }^{2}$ da banda Los Bregas. A despedida se inicia quando Tony entoa os versos de Eu voltarei $i^{3}$-- canção descrita como um "brega marcante dos anos 90" no YouTube --, creditada a Nelsinho Rodrigues e Aninha. Eles continuam cantando a canção em dueto em outros ambientes na sequência: Ver-o-Peso e a beira do rio. Quando Tony aparece já ocupando novamente a embarcação, ele canta Tchau tchau, amor (1986) de Ivan Peter que não consta nos créditos. Ela permanece triste na beira do rio enquanto a embarcação se distancia, o refrão de Eu voltarei cantado em dueto finaliza o episódio.

O episódio final da série gira em torno de Keila Gentil, vocalista da Gang do Eletro:

Após ver o seu futuro na bola de cristal de Valéria Paiva (Banda Fruto Sensual), Keila Gentil (Gang do Eletro) embarca numa aventura eletrizante de carona no marmita de Billy Brasil, e com suas amigas Rebeca Lindsay e Viviane Batidão, vão para a aparelhagem encontrar o traficante do amor Edilson Moreno (SAMPLEADOS - 5º. EPISÓDIO, 2015).

Ao início vemos a cantora na Estação das Docas entoando Ao pôr do sol de Teddy Max: há uma atmosfera onírica nessa abertura dada pelo filtro usado nas imagens. O cantor Edilson Moreno é o primeiro a contracenar com Keila: eles dançam juntos naquele ambiente. A segunda sequência começa com Valéria Paiva em uma sala escura

1 No link apresentado nessa página somos levados a um vídeo da canção no próprio YouTube que nos informa que os créditos corretos seriam dados à Banda Tribus.

2 Versão de Das model do Kraftwerk.

3 Versão de Making love out of nothing do Air Supply. 
manuseando uma bola de cristal enquanto canta trechos de Declaração de amor da Banda Sayonara. Keila Gentil também faz parte da cena cantando com a vidente o refrão "bola de cristal pra te mostrar/que a vida inteira eu vou te dar". Ao fim dos versos, a música é interrompida por uma sonoridade mais sombria eValéria canta, para Keila, um trecho da canção Xirley (2011), famosa na voz de Gaby Amarantos. Quando ela entoa os versos "e se tu for na aparelhagem, tu vai ver só", a cena se encerra. Há um corte para três mulheres andando em um shopping ostentando sacolas -- a imagem nos lembra o filme As patricinhas de Beverly Hills. A canção cantada por Rebeca Lindsay, ao lado de Keila e Viviane Batidão, é Na balada pop da Banda Maria Eugênia. Quando a cantora entoa o refrão "hoje eu vou pra aparelhagem", as três fazem uma coreografia marcante, o "treme", um balanço contínuo e ritmado dos ombros. A cena continua com Billy Brasil: ele está no estacionamento do shopping ao lado de um carro branco com o portamalas aberto e canta "gatinha, vem aqui, vem conhecer o som que esse carro tem..." do Brega da marmita de Jurandir. Os gestos sexualizados do cantor bem como o trocadilho do refrão são reprovados pelas garotas que lhes dão as costas e saem andando. A próxima sequência se dá em uma casa noturna: vemos um palco onde se lê "La Musique", luzes, lasers e fumaça ambientam a cena. No centro do palco, rodeada de dançarinos, temos Viviane Batidão vestindo um collant "tipo" maiô vermelho brilhante dançando como em um show convencional. Ela canta Luxuoso JackSom da Banda Fruto Sensual seguida de Ouro Negro do Skema Dance que tem, no refrão, a participação de Keila Gentil e Rebeca Lindsay, que agora habitam a plateia. Na sequência, o cantor Edilson Moreno, abraçando May Love e Suanny Batidão, entoa os versos de Traficante do amor (1996) de Wanderley Andrade. Logo em seguida, Keila Gentil, de vestido negro com decote marcante, sai do banheiro enquanto canta os versos de Piranha do banheiro da banda Aparelhagens. Há um corte no instrumental e Keila, ao lado de Viviane Batidão e Rebeca Lindsay, começa a cantar Pra me conquistar (2005) creditada à banda Calypso. A canção Melô do ladrão (1997), creditada a Wanderley Andrade, entoada por Edilson dá sequência às ações: os versos "eu sou ladrão, meu bem, vou roubar seu coração" são seguidos pelo refrão de Pra me conquistar cantado por Keila. Nesse momento, o par se encontra e dança a dois como no início do vídeo. A última música, cantada por vários personagens da série em tom festivo, é Xirley: seu refrão "eu vou samplear, eu vou te roubar" é como uma assinatura e trilha para um beijo entre Keila Gentil e Edilson Moreno.

Ao final dessa descrição surgem questões que, inevitavelmente, nos chamam atenção: uma delas é a marcante incompletude no que diz respeito aos créditos das músicas. Informações como autoria, ano de lançamento e até mesmo aquele que seria o performer original ou mais conhecido da canção seriam dadas em links nas páginas do YouTube 
de cada episódio. Há, no entanto, links quebrados ou mesmo informações discordantes entre o que nos é oferecido nos créditos e o que o link nos informa. Isso se faz evidente na nossa descrição dado que não conseguimos encontrar em outras fontes tais dados.

Outra imprecisão que merece menção é relativa ao ano de lançamento das canções. Os links para as versões supostamente originais acabaram nos forçando a buscar informações em plataformas tais como o Dicionário Cravo Albin, Wikipedia e sites dedicados aos artistas e ao brega paraense: com raras exceções encontramos verbetes no Cravo Albin e na Wikipedia -- esse é o caso mais comum entre os artistas atuantes desde os anos 1980 tais como Teddy Max e Frankito Lopes. Em outros casos, como ocorre com Wanderley Andrade e Banda Xeiro Verde -- atuantes desde os anos 1990 --, temos sites oficiais onde informações mais precisas e confiáveis são hospedadas. Por sua vez, quando a canção pesquisada já é parte do universo do tecnobrega -- a partir de 2002 (LEMOS; CASTRO, 2008) - quase não há qualquer informação além daquilo que encontramos em sites de streaming tais como o YouTube e o Palco MP3: nesses casos, é como se tivéssemos que confiar na data de lançamento como algo relativamente coincidente com a data da postagem nessas plataformas.

De qualquer forma, o que guia metodologicamente nossas observações sobre essas narrativas é a seguinte questão: o que a websérie Sampleados opera através de suas narrativas? Poderíamos pensar em várias portas de entrada para comentar como performaticamente esse objeto apresenta muitos traços que poderiam ser relacionados a uma espécie de identidade formal do brega paraense: as temáticas românticas e também bem humoradas inscritas no canto e no que é cantado; os figurinos de um modo geral extravagantes dos atores e atrizes em cena; há uma gestualidade nas danças que indica certa padronização performática dos artistas; a presença marcante de signos espaciais e territoriais que evidenciam a relação entre o brega paraense e a cidade de Belém.

De saída notamos que as canções funcionam como elementos determinantes da organização visual de cada episódio: a websérie aproxima-se em muito da linguagem do videoclipe exatamente por trazer, nas imagens, uma espécie de complemento -- por vezes redundante -- aos sentidos forjados na dimensão sonora em suas narrativas. Janotti Junior e Thiago Soares (2008) reconhecem os videoclipes como possíveis extensões das canções: eles vieram ajudando a articular uma espécie de imaginário audiovisual consolidando estrategicamente os gêneros musicais midiáticos que habitam o universo pop. Isso nos parece algo inovador no Sampleados na medida em que, de um modo geral, o brega paraense apoia-se em registros de shows hospedados em sites como o YouTube. Embora o Sampleados não seja exatamente um conjunto de videoclipes, há ali convenções que o aproximam desse universo.

Ao observar tais características formais, e a partir da leitura dos escritos de Paul Ricoeur em torno da tradicionalização e da historicização de narrativas canônicas presentes em Tempo e narrativa (ROCOEUR, 2010), o que notamos como algo potente é a operação 
historicizante, algo documental, de Sampleados que se articula através de dois gestos: a compilação das canções e a escolha dos artistas convidados. Para que pudéssemos construir os argumentos e as interpretações que apresentaremos em seguida, fizemos uma exaustiva pesquisa sobre as canções e os artistas presentes nos diferentes episódios tomando-os como índices exemplares daquilo que vem se convencionando em torno da expressão brega paraense.

\section{O brega paraense segundo o tecnobrega: um presente interpretante}

Partindo dessas últimas observações, o que se coloca em jogo, a partir de nossas reflexões, é a institucionalidade de uma suposta tradição de música popular feita no Brasil que, nessa série, busca referir-se a si mesma e a determinado passado como maneira de legitimar-se. Em primeiro lugar, parece-nos que isso se apresenta como algo considerável exatamente pela dificuldade de registro, catalogação e organização de informações concernentes a uma complexa produção musical local que, sobretudo após os anos 2000, se expande de maneira desenfreada em circuitos fonográficos de circulação não convencionais tornando-se muito difusa (BARROS, 2011). Em segundo lugar, é preciso lembrar que o brega é, em um contexto mais amplo de nossa historiografia musical, um fenômeno que tem sido pouco estudado tal como nos lembra Paulo César de Araújo na introdução de seu livro Eu não sou cachorro não (2002):

\footnotetext{
Sucesso de norte a sul do país, patrimônio afetivo de grandes contingentes das camadas populares, esta vertente da nossa canção romântica tem sido sistematicamente esquecida pela historiografia da música popular brasileira. Nas publicações referentes à década de 70, de maneira geral são focalizados nomes como os de Chico Buarque, Elis Regina, Gilberto Gil, Milton Nascimento, e discos como "Sinal fechado", "Falso Brilhante" "Clube da Esquina", todos, sem dúvida, representativos, mas que na época eram consumidos por um segmento mais restrito de público, localizado na classe média. O que a maioria da população brasileira ouvia eram outras vozes e outros discos.

Não dá mais para dissimular ou esconder. A produção musical "brega" ou "cafona" é um fato da nossa realidade cultural e, assim como a da bossa nova ou a do tropicalismo, precisa ser pesquisada e analisada (ARAÚJO, 2005, p. 15-16).
}

O autor se refere a um brega forjado no final dos anos 1960, altamente consumido na década seguinte através do rádio e da venda de discos. Notamos, porém, similaridades ao tematizarmos sua vertente amazônica: o brega paraense parece ser refém de algo semelhante embora também seja muito popular do ponto de vista numérico de consumo seja em festas, seja em shows, seja ainda em vizualizações/escutas na internet ou mesmo na venda de discos -- lembrando que a Banda Calypso é parte desse universo tendo vendido, ao longo de 16 anos, mais de 15 milhões entre discos e DVDs (BANDA CALYPSO, 2015). 
É talvez por isso que o Sampleados procure resgatar esses artistas e essas canções que são parte de um fenômeno que tem grande força cultural e identitária: o brega no Pará é algo que ganha traços de uma tradição viva inscrita nas mais variadas instâncias de sociabilidade (COSTA, 2003).

No ano 2000, tomamos contato com uma série documental intitulada Música do Brasil através da MTV. Tratava-se de um projeto de grandes proporções que, além dos 15 episódios televisivos de meia hora dirigidos por Belisário Franca e produzidos por Hermano Vianna, contou com um livro de fotografias (VIANNA; BALDAN, 2000) e com 4 discos produzidos por Beto Villares e novamente por Hermano Vianna. Um dos episódios da série, dedicado às formas de utilização da guitarra elétrica em variadas partes do Brasil, temos um trecho de mais de cinco minutos que faz ponte entre a jovem guarda e o brega paraense dos anos 1990. Ali havia depoimentos de músicos que seriam importantes agentes daquela cena, dentre eles Chimbinha, Kim Marques e Wanderley Andrade. Na entrevista, temos algumas falas curiosas:

Chimbinha: Nós pegamos a jovem guarda, né, e colocamos no ritmo nosso aqui do brega... Com ajuda aqui do maestro Edi Silva [...]. Pegamos um pouco do funk, pegamos um pouco do reggae, aí eu coloquei a guitarra no ritmo do... do calipso.

Kim Marques: Eu acredito que... é... tá no sangue. As pessoas que moram em Belém do Pará, do mesmo jeito que nascem gostando do carimbó, nascem gostando do brega.

Chimbinha: Acho que não dá mais pra chamar de brega. Tem nada de brega aí [...] (CHIMBINHA, KIM MARQUES E WANDERLEY ANDRADE, 2013, grifos nossos).

Ao fim dos depoimentos, entrecortados por imagens dos músicos tocando enquanto casais dançam a dois em uma embarcação em Belém, aparece um close do rosto de Gilberto Gil que complementa: "Chimbinha, com 23 anos, já colocou sua guitarra em mais de 400 discos paraenses. Um desses discos lançou Wanderley Andrade, o ídolo louro do brega.". No livro Música do Brasil (2000), temos o seguinte texto de Vianna:

Quando Roberto Carlos colocou em segundo plano as guitarras elétricas e se transformou em cantor romântico acompanhado de orquestras, a fórmula inventada pela jovem guarda se descentralizou, primeiro passando pelo Goiás de Amado Batista, depois pelo Pernambuco de Reginaldo Rossi, até chegar ao Pará do ex-governador Carlos Santos, também cantor brega, autor de dezenas de discos.

Hoje Belém é a capital do novo brega. Centenas de CDs são lançados anualmente, em princípio para um consumo regional, mas que começa a se alastrar para o Nordeste. Os músicos locais já nem chamam o que fazem de brega, dizem que é "calipso", música mais "sofisticada" (VIANNA; BALDAN, 2000, s/p, grifos nossos).

Esses dois excertos apontam duas questões que nos interessam a partir de nossa leitura do Sampleados. Uma delas reside nos testemunhos que colocam o brega como 
um importante signo cultural do Estado do Pará e a série parece endossar tal consideração. A outra se refere à tentativa de demonstrar que esse fenômeno musical encontra raízes na Jovem Guarda. Nesse caso parece haver discordância, pois a roupagem eletrônica e pop empregada nas canções nos diz que o brega, pelo menos em tempos atuais, busca referir-se a outras tradições. Instaura-se um campo de disputas nessas diferentes narrativas.

Paul Ricoeur, em sua discussão em torno da noção de tradição no capítulo Por uma hermenêutica da consciência histórica (2010), defende que é tarefa do historiador tomar o passado como obra inacabada, aberta e suscetível de desconstruções. Nesse sentido, o autor tenta demonstrar que a tradição não deve ser entendida como um depósito de relíquias inalteráveis ou mesmo como uma prisão ideológica; "[...] é preciso lutar contra a tendência de só considerar o passado sob o ângulo do acabado, do imutável, do findo." (RICOEUR, 2010, p. 368). A tradição -- no singular -- seria como um mediador institucionalizado que busca cristalizar os sentidos do passado sob o signo do verdadeiro. “Ela não é somente um intervalo de separação, mas um processo de mediação, balizado [...] pela cadeia de interpretações e reinterpretações das heranças do passado." (ibidem, 2010, p. 375). Seriam, segundo o autor, o conjunto de coisas já ditas, ouvidas e recebidas a partir de cadeias legitimadas de interpretação e reinterpretação. Ricoeur convoca a questão da legitimidade para tratar do termo como uma instância que "designa a pretensão à verdade (o ter-por-verdadeiro) oferecida à argumentação no espaço da discussão" (RICOEUR, 2010, p. 387, grifos originais). A tradição, portanto, é como um lugar de credibilidade no campo da mediação do passado.

Um possível -- e necessário -- contraponto a esse caráter autoritário residiria, então, na noção de tradicionalidade que aponta para um potencial mais dinâmico dessas mediações:

Ela significa que a distância temporal que nos separa do passado não é um intervalo morto, mas uma transmissão geradora de sentido. Antes de ser um depósito inerte, a tradição é a operação que só pode ser entendida dialeticamente na troca entre o passado interpretado e o presente interpretante (RICOEUR, 2010, p. $377-$, grifos originais).

A partir dessa compreensão nos tornamos capazes de observar as contradições que resistem às pretensões de verdade da tradição. É como se fôssemos convocados a reabrir o passado, afinal a tradicionalidade seria aquilo que promove a transmissão de múltiplas tradições, designando "um estilo formal de encadeamento que garante a continuidade da recepção do passado [...]." (RICOEUR, 2010, p. 386-387). Esse caráter de reciprocidade entre a eficácia dos relatos históricos e nossas experiências no presente é algo que revela as potencialidades concernentes aos processos de recepção e transmissão do passado operados através da tradicionalidade.

Embora haja imprecisões bem como um aparente descuido presentes nas informações trazidas nos créditos, entendemos Sampleados como uma proposta de encadeamento 
histórico não linear do brega paraense. Ao ser apresentada como resultante de uma produção local de Belém, a série nos convoca a reconhecê-la como um objeto legítimo e, aparentemente, coerente em sua versão para um passado do fenômeno musical em questão: nesse sentido, a presença de artistas como Edilson Moreno e Wanderley Andrade -- que têm suas carreiras iniciadas em meados dos anos 1990 quando o bregacalypso ganha sua formatação -- pode ser uma espécie de atestado de autenticidade do relato da série. Soma-se a isso a própria compilação de canções ali apresentadas creditadas a artistas de uma espécie de "velha guarda do brega paraense" tais como Ivan Peter, Frankito Lopes e Teddy Max . Mas há canções e artistas de tempos mais recentes que compõem o Sampleados e eles já fazem parte do universo daquilo que é chamado de tecnobrega.

Em um livro dedicado ao consumo e circulação do tecnobrega (LEMOS; CASTRO, 2008), há um trecho que aponta algumas relações entre essa vertente mais atual do gênero e suas heranças:

O tecnobrega nasceu do brega tradicional, produzido nas décadas de 1970 e 1980, quando se formou o movimento do gênero no Pará. Na década de 1990, incorporando novos elementos à sua tradição, os artistas do estado começaram a produzir novos gêneros musicais, como o bregacalypso, influenciados pelo estilo caribenho. No início dos anos 2000, por volta de 2002, surgiu o tecnobrega. Mais recentemente, vieram o cyber-tecnobrega e o bregamelody, todos influenciados pela música eletrônica, que circula mundialmente na web (LEMOS; CASTRO, 2008, p. 21-22, grifos nossos).

Aqui, o brega paraense aparece diretamente relacionado a uma ideia de tradição: algo já dotado de uma história singular, relacionado a certa movimentação no estado e que vai se reinventando e se derivando em subgêneros ao longo dos anos ao se relacionar com novidades de cada época, sejam mercadológicas sejam estilísticas. Se há uma tradição referenciada nesse relato, há, ao mesmo tempo, uma espécie de tentativa de validação daquela que seria a mais recente e inovadora versão do brega, o tecnobrega: nos termos de Ricoeur (2010), demonstra-se a sedimentação do brega enquanto um estilo formal de textualidade musical operada por um presente interpretante garantindo certa continuidade da recepção e organização de um passado -- bem como sua legitimidade.

O Sampleados, como sugerimos, parece ser uma espécie de representante dessa mesma vertente ao apresentar uma textura sonora completamente eletrônica: fora as vozes, não há qualquer instrumento microfonado na composição das músicas, tudo ali faz referência a uma "textura tecnobrega". A produção musical, inclusive, ficou a cargo do produtor, DJ e cantor Will Love da Gang do Eletro, um dos expoentes do tecnobrega atual.

Tal como afirma Barros (2009), o tecnobrega pode ser enquadrado naquilo que Simone Pereira de Sá (2003) chama de música eletrônica popular brasileira. Assim, mesmo

4 No final de 2015, Ao pôr do sol, famosa na interpretação de Teddy Max, foi considerada, a partir de votação popular, a canção mais representativa de Belém na ocasião da comemoração de seus 400 anos (G1 PA, 2015). 
as canções mais "clássicas" resgatadas pela série referem-se a uma textualidade sonora análoga à do mais recente tecnobrega, que é representado por canções como Na balada pop, Você vacilou, Tic tic tac e Xirley. Algo semelhante se dá com a presença de músicos como Keila Gentil, Viviane Batidão e Tony Brasil, um dos precursores do tecnobrega (LEMOS; CASTRO, 2008).

\section{Da legitimidade do brega no Sampleados}

A história do brega paraense que se edifica no Sampleados opera algumas exclusões. Em primeiro lugar, deixa de lado a influência de gêneros latinos e caribenhos como o merengue e a cúmbia -- muitos deles designados localmente como lambada -- que teriam sido elementos imprescindíveis para o gênero a partir dos anos 1990 (VIANNA, 2010). Dessa maneira, mesmo nesse gesto de resgate de canções e artistas que teriam marcado parte dessa história, inevitavelmente algo fica de fora: isso evidencia o passado como um terreno de disputas e escolhas em meio a uma dialética que envolve rememorações e esquecimentos.

Uma segunda operação excludente, embora menos evidente, nos parece importante dado que faz eco a uma percepção que tivemos a partir de uma incursão etnográfica que empreendemos em Belém entre outubro e novembro de 2016. O Sampleados constrói para si um passado ao arquitetar, através de sons e imagens em performance, traços de uma rica e múltipla tradição de música popular midiática. A partir de nossa leitura, notamos que esse fenômeno -- que perdura e se reinventa com a passagem dos anos -- não aponta para relações com aquilo que se apresenta como grande referência da historiografia da música popular feita no Brasil: a MPB.

Não se trata exatamente da construção de uma história do brega como resultante de um contraponto unânime à MPB. Há diversas pistas que indicam possíveis interlocuções entre tais domínios tais como a histórica aproximação dos tropicalistas à música cafona e à jovem guarda ao final dos anos 1960. O autor Celso Favaretto (2000), inclusive, toma isso como um dos procedimentos mais ricos do movimento ${ }^{5}$. O que nos parece importante salientar é que a websérie -- bem como diversos artistas com os quais dialogamos recentemente em Belém -- não parece se preocupar em fazer referências a essas tradições comumente ligadas a isso que veio se convencionando em torno da sigla. Afinal, tal como nos adverte Henry Burnett,

[...] música popular hoje é, antes de tudo, a expressão dessa verdade musical, na medida em que revela no caso do Brasil [...] as várias faces do povo que a produz e consome -- o que contraria a hipótese inicial e indica que o Brasil também possui outras imagens além dessa face única que nos acostumamos a aceitar como normal (BURNETT, 2015, p. 185, grifos do autor).

5 Para além disso, lembramos de gestos pontuais como as versões de Caetano Veloso para canções de compositores desse universo desde os anos 1970 tais como Odair José, Peninha e Wando. Vale a pena lembrar também do mais recente trabalho de Fafá de Belém, Do tamanho certo para o meu sorriso (2015): a intérprete convoca os músicos belenenses Manoel Cordeiro e Felipe Cordeiro para a produção imprimindo uma textura sonora bem próxima ao tecnobrega para canções como Ao pôr do sol que também é parte do repertório do Sampleados. 
Podemos pensar que o Sampleados, nesse sentido, nos apresenta uma face minoritária, periférica de nossa música popular: o brega paraense surge aqui como um fenômeno que busca, através de gestos autorreferencial, afirmar-se como uma importante expressão cultural. Essa operação posta em prática indiretamente pela série não apenas evidencia uma espécie de renúncia a passados "mais tradicionais" de nossa música popular, como demonstra que: a) a história da música popular feita no Brasil é um terreno de disputas muito complexo; b) mesmo diante da falta de narrativas, arquivos e objetos reconhecidos, catalogados e monumentalizados, o Sampleados, ao operar tal escrita historiográfica, busca estabilizar uma memória musical coletiva explicitando um projeto de conservação para o futuro do que é, em parte, o brega paraense.

Rafael José Azevedo é doutorando no Programa de Pós-Graduação em Comunicação e Sociabilidade Contemporânea da UFMG. Participa do Núcleo de Estudos Tramas Comunicacionais: Narrativa e Experiência. Atua também como compositor, arranjador e produtor de áudio.

rafaeljoseazevedo@gmail.com

\section{Referências}

ARAÚJO, P. C. Eu não sou cachorro não. Rio de Janeiro: Record, 2005.

BARROS, L. G. Tecnobrega, entre o apagamento e o culto. In: Revista Contemporânea, n. 12, 2009. Disponível em <http://www.contemporanea.uerj.br/pdf/ed_12/contemporanea_n12_07_lydia.pdf>. Acesso no dia 19 fev 2016.

Tecnobrega: a legitimação de um estilo musical estigmatizado no contexto do novo paradigma da crítica musical. Tese (Doutorado em Comunicação) - Universidade Federal de Pernambuco (PPGCOM/UFPE), Recife, 2011.

BURNETT, H. Cultura popular, música popular, música de entretenimento: o que é isso, a MPB?. In: IANNINI, G.; GARCIA, D.; FREITAS, R. (Orgs.). Artefilosofia: antologia de textos estéticos. Rio de Janeiro: Civilização Brasileira, 2015.

COSTA, A. M. D. Festa na cidade: o circuito bregueiro de Belém do Pará. Belém: Eduepa, 2009.

FAVARETTO, C. Tropicália: alegoria, alegria. Cotia: Ateliê Editorial, 2000.

GARCíA, P. H. Las Webseries: Evolución y características de la ficción española producida para Internet. In: Revista F@ro, no 13. Valparaíso, Chile (2011). p. 94-104.

G1 PA. 'Ao pôr do sol' é eleita música que representa 400 anos de Belém. In: G1 - site de notícias. Postado no dia 16 dez 2015. Disponível em <http://g1.globo.com/pa/para/belem-400-anos/noticia/2015/12/ ao-por-do-sol-e-eleita-musica-que-representa-400-anos-de-belem.html>. Acesso no dia 21 fev 2016.

JANOTTI JR., J.; SOARES, T. O videoclipe como extensão da canção: Apontamentos para análise. In: Revista Galaxia, n. 15. São Paulo, jun. 2008. p. 91-108. 
LEMOS, R.; CASTRO, O. Tecnobrega: o Pará reinventando o negócio da música. Rio de Janeiro: Aeroplano, 2008.

RICOEUR, P. Tempo e narrativa 3: o tempo narrado. São Paulo: Editora WMF Martins Fontes, 2010.

SÁ, S. P. Música eletrônica e tecnologia: reconfigurando a discotecagem. In: Anais do XII COMPÓS, Recife: 2003. Disponível em: <http://www.compos.org.br/data/biblioteca_1051.PDF>. Acesso no dia 20 fev 2016.

VIANNA, H.; BALDAN, E. Música do Brasil. São Paulo: Editora Abril, 2000.

VIANNA, H. A música paralela. In: Caderno Mais+, Folha de S.Paulo. São Paulo, 12 out 2010, p. 6. Disponível em <http://www1.folha.uol.com.br/fsp/mais/fs1210200306.htm>. Acesso no dia 15 abr 2014.

\section{Sites consultados}

BANDA CALYPSO: site oficial, 2015. Disponível em <http://www.bandacalypso.com.br/>. Acesso: 20 fev 2016.

DICIONÁRIO CRAVO ALBIN DA MÚSICA POPULAR BRASILEIRA. Desenvolvido pelo Instituto Cultural Cravo Albin. Apresenta conteúdo enciclopédico. Disponível em <http://www.dicionariompb. com.br/>. Acesso no dia 17 fev 2016.

PALCO MP3: o maior site de música independente do Brasil. Disponível em <https://palcomp3. com/>. Acesso no dia 18 fev 2016.

WANDERLEY ANDRADE: site oficial, 2011. Disponível em <http://www.wanderleyandrade.com. br/>. Acesso em: 17 fev 2015.

WIKIPÉDIA. Desenvolvido pela Wikimedia Foundation. Apresenta conteúdo enciclopédico. Disponível em <https://pt.wikipedia.org/wiki/>. Acesso no dia 17 fev 2016.

\section{Videografia}

Chimbinha, Kim Marques e Wanderley Andrade. Postado por Dja Correia em 31 ago 2013. 5 minutos. Disponível em <https://www.youtube.com/watch?v=5KbTTzE2Ne8>. Acesso no dia 23 ago 2014.

Sampleados $\mathbf{1}^{\mathbf{0}}$. Episódio. Postado por Platô Produções em 05 jun 2015. 3 minutos e 45 segundos. Disponível em <https://www.youtube.com/watch?v=WfFgjRGoLXw>. Acesso no dia 11 fev 2016.

Sampleados - $\mathbf{2}^{\mathbf{0}}$. Episódio. Postado por Platô Produções em 19 jun 2015. 3 minutos e 19 segundos. Disponível em <https://www.youtube.com/watch?v=BSUutHbFb54>. Acesso no dia 11 fev 2016.

Sampleados - $3^{\mathbf{0}}$. Episódio. Postado por Platô Produções em 03 Jul 2015. 3 minutos e 44 segundos. Disponível em <https://www.youtube.com/watch?v=aXmmlX6cVSg>. Acesso no dia 11 fev 2016.

Sampleados - 4º . Episódio. Postado por Platô Produções em 17 jul 2015. 4 minutos e 40 segundos. Disponível em <https://www.youtube.com/watch? $v=1$ SAQhL45fFA $>$. Acesso no dia 11 fev 2016.

Sampleados - 5 $\mathbf{5}^{\mathbf{}}$. Episódio. Postado por Platô Produções em 02 out 2015. 5 minutos e 30 segundos. Disponível em <https://www.youtube.com/watch?v=i-a58JJPhBk>. Acesso no dia 11 fev 2016. 